\title{
FANTASMAGORIAS DO TEMPO APAGAMENTO DA MEMÓRIA E INVENÇÃO \\ DA HISTÓRIA NO ESPAÇO BRASILEIRO
}

\author{
Ettore Finazzi-Agrò \\ Sapienza Universidade de Roma
}

RESUMO: 0 ensaio procura resgatar os muitos silêncios e as omissões recorrentes que constelam a história brasileira remetendo, sobretudo, para a magistral recapitulação das teorias historiográficas apresentada no livro de Paul Ricœur L'histoire, la mémoire, l'oubli. A conexão entre memória e esquecimento, da qual depende boa parte da historiografia contemporânea, leva, de fato, a pensar o tempo brasileiro na sua inconsequência ou na sua intempestividade, justificando a proposta, avançada por Raul Antelo, da história do Brasil como uma possível "genealogia do vazio".

PALAVRAS-CHAVE: Vazio; Genealogia; Fantasmagoria.

\author{
TIME'S PHANTASMAGORIAS \\ THE DELETION OF THE MEMORY AND THE INVENTION \\ OF HISTORY IN THE BRAZILIAN SPACE
}

ABSTRACT: The essay seeks to recover the many silences and recurrent omissions that cross the Brazilian history, mainly referring to the masterful recapitulation of the historiographical theories presented in the Paul Ricœur's book L'histoire, la mémoire, I'oubli. In fact the connection between memory and forgetfulness, on which much of contemporary historiography depends, leads us to think of Brazilian time in its inconsequence or its untimeliness, justifying the proposal advanced by Raul Antelo of the history of Brazil as a possible "genealogy of emptiness".

KEYWORDS: Nothingness; Genealogy; Phantasmagoria.

Ettore Fnazzi-Agrò é professor titular de Literatura Portuguesa e Brasileira na Sapienza Universidade de Roma e diretor das revistas Letterature d'America (Roma) e Studi Portoghesi e Brasiliani (Pisa). 


\title{
FANTASMAGORIAS DO TEMPO APAGAMENTO DA MEMÓRIA E INVENÇÃO DA HISTÓRIA NO ESPAÇO BRASILEIRO
}

\section{ETTORE FinAZZI-AgRò}

\begin{abstract}
A história é objeto de uma construção cujo lugar não é o tempo homogêneo e vazio, mas um tempo saturado de "agoras". [...] O passado só se deixa fixar, como imagem que relampeja irreversivelmente, no momento em que é reconhecido.

Walter Benjamin, Teses de filosofia da história
\end{abstract}

A amizade, como a vida para Riobaldo, pode ser às vezes muito perigosa. Ser amigo de Raúl comporta, com efeito, um perene sentimento de insuficiência perante a sua imensa erudição e a sua cultura aparentemente sem limites. Para dar um exemplo recente, quando the anunciei que eu ia participar de um seminário na Maison de l'Amérique Latine em Paris, ele me respondeu lembrando que a sede dessa instituição tinha sido a moradia de Charcot; que o jovem Freud foi visitar, intimidado, o ilustre psiquiatra; que no jardim daquela casa existe um restaurante frequentado por executivos e que perto dela há uma bela loja de roupas de inspiração oriental e uma luxuosa sapataria masculina. Um conjunto de informações que me deixou um tanto estarrecido, visto que eu não conhecia a história da Maison e nada sabia da relação entre Charcot e Freud, nem da presença do restaurante e tampouco da existência de lojas elegantes perto da Casa.

Ser amigo de Raúl comporta, então, um mergulho na nossa ignorância, ou melhor, uma queda no abismo da nossa (humana, demasiado humana) grosseria. Isso pode, evidentemente, provocar tentativas de emulação ou a vontade de ficar na nossa insciência, recusando de ser conduzidos por ele no seu universo de informações, de saberes, de conhecimentos. Eu assisti, de fato, aos dois efeitos que a esmagadora massa de referências que ele pode colocar em jogo produzem sobre as pessoas: aceitação ou recusa de um homem de tão vastos conhecimentos, que pode ser considerado um guia e um mestre precioso ou uma pessoa arrogante e presunçosa. Convivendo com ele, ao longo de muitos anos - embora de modo intermitente -, sei por certo que ele não tem nada do frio estudioso, vangloriando-se da sua imensa e variada cultura, mas que, pelo contrário, ele é uma pessoa sensível e generosa, dispensando, sem saber, os seus muitos saberes. 
Eu, que me orgulho de ser amigo de Raúl - e aqui concluo com os elogios para não aparecer demasiado bajulador e puxa-saco -, considero esta oportunidade de refletir sobre a relação entre arqueologia e história um modo para homenagear a vastidão dos seus interesses, a partir, justamente, da sua capacidade de vasculhar arquivos e de sua natureza de incansável investigador da história da arte e da literatura. Confesso aliás, desde logo, que o meu ponto de partida não é exatamente uma obra de Raul e sim um livro escrito por um famoso filósofo francês que, aos seus 87 anos e cinco anos antes de morrer, publicou uma obra que pode ser considerada uma espécie de legado para as gerações futuras e uma recapitulação brilhante do seu longo percurso de pensador e estudioso. Refiro-me, evidentemente, a Paul Ricœur e ao seu La mémoire, l'histoire, l'oubli, publicado em 2000. ${ }^{1}$ Ele que tinha sido, para além de muitos outros merecimentos, o mais importante investigador moderno da relação entre tempo e narrativa, nos ofereceu (e a oferta é tanto mais parecida com o dom - noção aliás amplamente tratada no interior do livro -, enquanto o autor fez questão que a primeira edição saísse em edição econômica, na coleção Points das Éditions du Seuil), nos presenteou, então, com um panorama extremamente amplo e articulado das muitas propostas teóricas sobre o tratamento do tempo - e do passado em particular - na cultura ocidental, refletindo e conjugando as várias perspectivas e chegando a algumas conclusões que eu considero fundamentais, embora tenham sido amplamente debatidas e/ou criticadas por outros representantes da historiografia contemporânea.

A questão colocada por Ricœur, atravessando um livro tão extenso e denso, é, mais uma vez, a nossa relação com a temporalidade pretérita e os modos dos quais dispomos para a recontar. Afinal, o assunto é sempre aquele típico do ilustre estudioso francês, ou seja, o cruzamento entre temps e récit, tentando assim desvendar o lugar do sujeito, a maneira em que ele se relaciona com o acontecido e é por ele condicionado. As possíveis concatenações entre presente e passado ficam, portanto, no primeiro plano, se abrindo, na parte final do livro, para a questão do esquecimento, para um momento, que eu chamaria, de certa forma, "catártico", de apagamento da experiência (e da experiência dolorosa, em particular) através do pardon, isto é, graças ao ato de doar o perdão - jogando com a ambivalência entre o latim clássico donum e as suas derivações perdonum e condonum no latim medieval.

Um grande número de teorias historiográficas é analisado no livro, que não se esquiva, para além disso, de penetrar também nos territórios pró-

${ }^{1}$ RICEFUR, Paul. La mémoire, l'histoire, l'oubli. Paris: Seuil, 2000 
prios da psicologia, da sociologia ou da antropologia, sempre no intuito de desvendar o significado e as perspectivas possíveis do nosso estar no tempo. Confesso, aliás, que quando escrevi, anos atrás, um ensaio sobre a historiografia literária no Brasil, tomando emprestado de Martin Heidegger o tema do tempo (pré)ocupado, eu tinha, na verdade, como base as considerações de Paul Ricœur e a sua análise dos conceitos heideggerianos de Cuidado e de Intratemporalidade. Naquele breve texto, de fato (incluído agora, revisto e refundido, no meu livro Entretempos), eu lançava uma proposta de revisão do tempo (e do tempo literário, em particular) no contexto brasileiro, porque não há dúvida que a condição pós-colonial do país coloque um problema incontornável quanto ao tratamento do passado e à sua relação com o presente. ${ }^{2}$

De fato, a ruptura com o país colonizador comporta também uma laceração na sequência entre passado e presente, levando para uma diferente maneira de narrar o tempo, em que a ficção preenche o lugar vazio (ou esvaziado) da origem. Nesta perspectiva, Ricœur parece por um lado admitir, na preservação da memória e na procura das causas do presente, uma linhagem que, a partir do testemunho, passa pelo arquivo para chegar à história, enquanto, pelo outro, afiança e compartilha a tese de Michel de Certeau sobre "l'absent de l'histoire". ${ }^{3}$ Esse duplo olhar sobre o passado - um baseado na série oralidade, escrita e narrativa, ou seja, na passagem ativa do documento ao monumento, e outro fundado sobre a figura passiva, silenciosa do ausente, daquele que, tendo vivido num tempo pretérito e sendo o verdadeiro sujeito e objeto da história, não pode todavia mais nem falar nem escrever - é muito útil, no meu entender, na avaliação do papel da historiografia no contexto brasileiro, visto que, como sublinharam tanto Süssekind quanto o próprio Raúl, o modo de retratar o passado assenta, nesse âmbito, sobre uma "genealogia do vazio" - embora seja difícil, ainda hoje, encontrar no Brasil uma prática historiográfica que corresponda plenamente a essa ausência constitutiva do tempo nacional. ${ }^{4}$

De fato, tanto na escrita da história quanto naquela artística temos a ver, por um lado, com a consciência culpada de alguns grandes intelectuais que souberam assumir o peso da falta e lamentar o incontornável alheamento da

2 FINAZZI-AGRÒ, Ettore. Entretempos: mapeando a história da cultura brasileira. São Paulo: Editora Unesp, 2013.

3 CERTEAU, Michel de. L'absent de l'histoire. In: Histoire et psychanalyse: entre science et fiction. 2. ed. Paris: Gallimard, 2002.

${ }^{4}$ ANTELO, Raul. Genealogia do vazio. Rivista di studi portoghesi e brasiliani, I, p. 57-68, 1999; SÜSSEKIND, Flora. "O escritor como genealogista”. In: PIZARRO, Ana (Org.). América Latina: palavra, literatura e cultura. v. 2. Campinas: Memorial Unicamp, 1994, p. 451-485. 
cultura brasileira que vem dessa não aceitação da ausência de um fundamento próprio (poderia citar as obras de Sérgio Buarque de Holanda ou de Antonio Candido, mas prefiro mencionar apenas a famosa definição de Paulo Emílio Salles Gomes sobre "a dialética rarefeita entre o não-ser e o ser-outro"5), enquanto, por outro lado, assistimos às tentativas incessantes de rasurar o vazio, isto é, de criar fetiches de identidade sobre os quais basear uma continuidade e uma norma consequencial, de fato inexistentes ou imaginadas. Penso, por exemplo, em Sérgio Romero ou em Afrânio Coutinho, grandes autores que tentaram inventar - a partir, cada um, de uma perspectiva diferente - uma coerência entre passado e presente na qual embasar uma ideia de Pátria e de comunidade nacional.

Nesse sentido, a atenção prestada por Paul Ricœur, por um lado, à sequencia necessária entre documento e monumento e, pelo outro, à fundamental e fundadora presença do ausente, poderia representar, para a historiografia brasileira, um ponto de partida extremamente produtivo. Quanto ao re-uso documentário, podemos desde já mencionar pelo menos dois grandes escritores brasileiros, um do século XIX e outro do século XX. O primeiro é obviamente José de Alencar que encheu o seu $O$ guarani de notas de rodapé, remetendo para os textos de cronistas e de eruditos de toda sorte no intuito de fundamentar o seu discurso romanesco. Esse uso instrumental das auctoritates não representa um caso isolado no âmbito da literatura brasileira do séc. XIX - o vamos encontrar, com efeito, em muitas outras obras do próprio Alencar e de outros escritores do período e, de forma muito mais refinada e paracientífica, até em Euclides da Cunha -, constituindo, afinal, um elemento diferenciador em relação, por exemplo, ao romance histórico europeu, no qual persiste, sim, a função pré-textual (e de pretexto) do falso manuscrito antigo, reencontrado de modo fortuito, mas onde em raros casos teremos, no paratexto, uma referência tão explícita e reiterada aos documentos históricos reais a fim de fundamentar a ficção. Aquilo para o qual tudo isso remete é uma falsificação do tempo do arquivo em vista da construção de um tempo histórico coerente com a arbitrária premissa documentária.

Nessa fantasmagoria histórico-ficcional, ou propriamente, nessa re-proposição de fantasmas de identidade, a figura mais apropriada de révenant é, obviamente, a do indígena, cumprindo, junto com a exaltação da natureza e com a reativação do mito do homem natural, a função de elo de conjunção

\footnotetext{
${ }^{5}$ GOMES, Paulo Emílio Sales. Cinema: trajetória no subdesenvolvimento. Rio de Janeiro: Paz e
} Terra, [1973] 1996, p. 90. 
imaginário entre passado e presente, entre arqueologia e história, entre ausência e presença. A esse estereótipo parece não escapar o outro escritor do século passado a quem me referi. Com efeito, mesmo indo na contramão do mito, contradizendo a bondade do homem e o caráter selvagem e programaticamente inculto da natureza ("a floresta e a escola"), também Oswald de Andrade nada faz mais de que reafirmar o papel fundamental e fundador da cultura indígena. E mais uma vez, essa identificação com o "ausente" se baseia num re-uso das fontes documentárias, tanto assim que na secção denominada "História do Brasil" da sua Poesia Pau-Brasil vamos reencontrar o emprego dos textos dos cronistas e viajantes europeus que já vimos em Alencar. A diferença, porém, é que lá onde o escritor romântico confundia, de forma instrumental, o documento com a ficção, o escritor modernista tenta, de modo irônico ou alheado, se apropriar das fontes em direção do presente, tornando poético, incongruente e polissêmico o documento. Em vez de uma narrativa imitando a história, teremos, então, uma história se tornando objeto ficcional e instaurando "um grande carnaval do tempo" (para parafrasear as palavras que Foucault dedicou à genealogia nietzschiana ${ }^{6}$ ), onde o arquivo é apenas um amontoado de rascunhos caóticos e não confiáveis, citando os quais, de forma estranhada, é possível reinventar o presente da nação e designar, de modo utópico, o seu futuro (basicamente, o famoso "matriarcado de Pindorama" sobre o qual Oswald irá voltar de maneira incansável quase até a sua morte).

Esse uso e abuso dos documentos nos leva mais uma vez, cotejando o livro de Ricœur, a nos interrogar sobre como funcionam a memória, a história e o esquecimento no espaço brasileiro: numa dimensão, justamente, onde, como afirmava o Conselheiro Aires, citado por Alfredo Bosi, "les morts vont vite" e onde relembrar o passado assume, às vezes, as cores negras e as andanças lutuosas de um rito de enterro. ${ }^{7}$ Inutilizando qualquer fetichismo identitário, excluindo qualquer aproveitamento ficcional e ufanista dos "ausentes", o que resta é, nesse sentido, apenas a lamentação indignada daqueles que assistiram, impotentes, aos fatos: das testemunhas ou dos supérstites que, como Euclides, tentaram erguer um monumento funerário às vítimas, resgatando o seu vozerio sem eco, desvendando no acontecido uma possibilidade irrealizada.

${ }^{6}$ FOUCAULT, Michel. Nietzsche, la généalogie, I'histoire. In: Philosophie. Anthologie. Paris: Gallimard, 2004, p. 393.

7 BOSI, Alfredo. O tempo e os tempos. In: NOVAES, Adauto (Org.). Tempo e história. São Paulo: Companhia das Letras, 1992. 
Acho curioso, nessa perspectiva, que, no índice analítico que se encontra no fim de La mémoire, l'histoire, l'oubli, o verbete Témoignage remeta para Document, como se o estudioso francês emparelhasse a figura da testemunha ou do histor (ou seja, etimologicamente, "daquele que viu") com aquela do arquivista - embora seja lícito duvidar se foi o próprio Ricœur que curou, materialmente, os índices. É curioso porque se há uma diferença notável entre os vários momentos da reconstrução histórica ela consiste, justamente, em primeiro lugar na não coincidência entre o testemunho e o documento arquivado e, em segundo lugar, entre o tempo arquivado e o tempo recontado.

De fato, como vimos nos casos de Alencar e de Oswald, a história brasileira, como aquela de todos os países pós-coloniais, vive e se alimenta dessa defasagem, dessa inconsequência entre o dado documentário e o seu aproveitamento, o que vai dar numa situação inatual ou intempestiva onde aquilo que conta não é a ordenação e a concatenação cronológica dos fatos e sim a com-presença dos tempos, ligada, mais uma vez, à instância atemporal e substantiva de um sujeito ausente. Já que, afinal, o que vale é a suposição fantasmática da origem ou das possíveis origens das quais descende, fatalmente, uma genealogia plural e anacrônica, ligada a aquilo que Ernst Bloch denominou como "contemporaneidade do não-contemporâneo"8 e que Reinhart Koselleck teorizou como conluio de passado, presente e futuro numa segmentação caótica de momentos diversos, dependendo da pluralidade das ideologias e do relacionamento delas com um tempo que se mostra, necessariamente, assíncrono. ${ }^{9}$

Nesse sentido, aquilo que parece prevalecer, no contexto brasileiro como, aliás, em muitos outros âmbitos nacionais -, é a natureza, ao mesmo tempo, conjectural e contingente da reconstrução histórica: conjectural por causa do uso instrumental e arbitrário das fontes documentais; contingente porque nela se dá aquilo que Giorgio Agamben definiu como realização efetiva de uma possibilidade: "o modo em que uma potência existe enquanto tal". ${ }^{10}$ Logo depois, de resto, o filosofo italiano acrescenta que justamente o caráter contingente (ou seja, "o possível posto à prova de um sujeito") é aquilo que, se colocando entre a langue e o arquivo, "[...] pretende uma subjetividade, sendo o que atesta, na própria possibilidade de falar, uma impossibilidade de

\footnotetext{
${ }^{8}$ BLOCH, Ernst. Erbschaft dieser Zeit. In: Werkausgabe. Bd. 4. Suhrkamp: Frankfurt, 1962.

${ }^{9}$ KOSELLECK, Reinhart. Vergangene zukunft. Zur semantik geschichtlicher zeiten. Frankfurt: Suhrkamp, 1979.

${ }^{10}$ AGAMBEN, Giorgio. Quel che resta di Auschwitz: l'archivio e il testimone. Torino: Bollati Boringhieri, 1998, p. 136.
} 
palavra." ${ }^{11}$ Aqui, como se vê, o acento é posto não sobre a diferença entre tempo do arquivo e tempo da história, mas sobre a relação conjuntural entre sujeito e objeto da reconstrução histórica, entre o gesto arqueológico do desenterro do passado e a faculdade da testemunha de falar em nome e por conta daqueles - dos "ausentes", mais uma vez - que não podem falar.

Considerar essa impossível possibilidade do testemunho é, a meu ver, particularmente importante na avaliação da história brasileira, visto que ela aparece constelada por silêncios ou por atos de fala virtuais, quase sempre omitidos pelos relatos históricos oficiais: aqueles do índio, como vimos, mas também aqueles das inúmeras pessoas que participaram e morreram durante a Cabanagem, a Sabinada, a Balaiada ou a guerra do Contestado - e, mais em geral, as vozes, os gritos e os esgares doloridos de todas as vítimas sem nome de uma repressão sangrenta, de todos aqueles que não deixaram rastros nos arquivos oficiais e de que a escrita da história dá conta apenas de modo conjetural. De fato, esses "homens infames", na sugestiva definição de Foucault, apesar do esquecimento ao qual os condenou a História, continuam nos enviando sinais que poderiam ser ordenados apenas dentro de um paradigma indiciário (para retomar uma expressão conhecida de Carlo Ginzburg), ou meIhor, no interior de um repertório sem ordenação consequencial e sem regras cronológicas, atestando todavia, na possibilidade teórica de assumir a palavra, a existência de um sujeito que não pode falar. ${ }^{12}$ Salvo em casos raros, a falta de testemunhos fiáveis é, no Brasil, o traço característico de um tempo em palimpsesto, de um tempo continuamente apagado e reescrito (re-inscrito) em vista de uma história fundada não sobre a memória arquivada, mas sobre o esquecimento compulsivo (de que a "Lei da Anistia" pode ser um exemplo claro e recente).

É justamente por isso que a minha proposta, para vencer a rasura ou o recalque daquela que Benjamin definia "a tradição dos oprimidos", foi a de construir, juntando pedaços desconectados, uma história da cultura brasileira não pautada pelo tempo do relógio e sim pela justaposição de imagens ou de figuras nas quais se condensa, por instantes, a memória de uma nação no curso do tempo - do seu tempo plural e inexequível. ${ }^{13}$ Uma história fora da

\footnotetext{
11 Ibidem, p. 136.

12 FOUCAULT, Michel. "La vie des hommes infâmes". In: Philosophie. Anthologie. Paris: Gallimard, 2004, p. 562-586; GINZBURG, Carlo. Spie. Radici di un paradigma indiziario. In: GARGANI, Aldo Giorgio (Org.). Crisi della ragione. Torino: Einaudi, 1979, p. 57-106.

13 BENJAMIN, Walter. Tesi di filosofia della storia. In: Angelus Novus. Saggi e frammenti. Trad. Renato Solmi. 4. ed. Torino: Einaudi, 1981.
} 
norma então, ou pelo menos, fora de uma concatenação causal de nomes e de fatos, uma história que seja, ao mesmo tempo, reconstrução arqueológica do passado e negação desse passado que, no icônico dinamismo da figura, não consegue passar. Porque é apenas nessa capacidade de constelar tempos heterogêneos, nessa não coincidência e nessa defasagem entre o poder-dizer e o dito (entre langue e parole, entre a instituição de um paradigma e a disposição sintagmática dos eventos), entre aquilo, enfim, que se apresenta com feito e perfeito no âmbito do arquivo e aquilo que fica sempre por-fazer e imperfeito pretendendo o gesto do arqueólogo - é nessa contingência, então, que habita não apenas o testemunho, mas mais em geral uma certa imagem da história e a própria história como sucessão caótica e heterogênea de figuras e como interrogação incessante desse caos e dessa heterogeneidade.

Acho, com efeito, que só considerando o decurso temporal, não como sequência ordenada de nomes rememorados e de fatos arquivados, e sim como pulular de figuras em que se amontoam e se condensam provisoriamente significados a serem decifrados, tanto no sentido sincrônico quanto diacrônico - ou melhor, conjugando sincronia e diacronia, repetição e diferença -; só, afinal, sob a forma de uma iconologia inconsequente ou, na esteira de Benjamin, de uma coleção de artefatos diversos, onde, nas imagens e nas coisas musealizadas, se cruzam tempos diferentes, podemos tentar montar uma história plausível, testemunhando a pluralidade das instâncias e das vozes já inaudíveis que nessas figuras, por instantes, se coalham - ecoando num presente que, sempre segundo Benjamin, "[...] não é transição, mas fica suspenso no tempo e é imóvel."14 Tempo do arquivo e tempo da história perdem assim os seus contornos, fluindo um no outro, um dentro e através do outro, deixando pairar uma interrogação que pretende uma hermenêutica sem fim e sem respostas certas.

A historiografia praticada por Raúl tem, a meu ver, exatamente esse caráter a mesmo tempo contingente e necessário, arqueológico e histórico, intempestivo e atento à evolução do panorama cultural, numa procura infindável daquilo que, no texto literário ou no produto artístico, faz dele um espelho - um espelho negro, porém, remetendo para o enigma - não apenas do passado, mas também do presente, nas suas múltiplas relações com outros tempos e outras dimensões da prática humana, com outros "artifícios". E para finalizar esta breve reflexão sobre o tratamento do tempo e sobre o seu questionamento no âmbito brasileiro assim como num contexto teórico muito mais am-

\footnotetext{
14 Ibidem.
} 
plo, eu gostaria de mencionar um grande filósofo e historiador da arte como Georges Didi-Huberman - não por acaso muitas vezes lembrado, nos seus ensaios, por Raúl Antelo. Ele afirmou de fato, no seu Devant le temps todo consagrado à relação complexa entre temporalidade e imagem, que na escrita da história a figura se apresenta como "concatenação de sutis anacronismos: fibras de tempo entremeadas, campo arqueológico a ser decifrado", ${ }^{15}$ recuperando, assim, o que, no passado refletido na linguagem icônica, se apresenta como sempre inatual ou intempestivo: isto é, uma memória tentando resgatar a ausência, uma memória do imemorável.

É nessa aporia, afinal, nesse anacronismo engolindo qualquer instância crono-lógica e qualquer obrigação consequencial, que podemos enfim redescobrir, a meu ver, o sentido multíplice do nosso confuso estar-no-mundo, fiIhos e pais de um tempo que, por um lado, é nosso no afastamento e no olvido e, pelo outro, nos institui na nossa genealógica, humana e fatal insuficiência.

15 [...] agencement d'anachronismes subtils: fibres de temps entremêlées, champ archéologique à déchiffrer. DIDI-HUBERMAN, Georges. Devant le temps. Histoire de l'art et anachronisme des images. Paris: Minuit, 2000, p. 36. [Tradução minha]. 